\title{
Galectin-3 drives oligodendrocyte differentiation to control myelin integrity and function
}

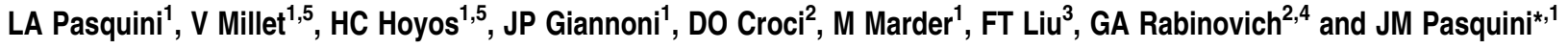

Galectins control critical pathophysiological processes, including the progression and resolution of central nervous system (CNS) inflammation. In spite of considerable progress in dissecting their role within lymphoid organs, their functions within the inflamed CNS remain elusive. Here, we investigated the role of galectin-glycan interactions in the control of oligodendrocyte (OLG) differentiation, myelin integrity and function. Both galectin-1 and -3 were abundant in astrocytes and microglia. Although galectin-1 was abundant in immature but not in differentiated OLGs, galectin-3 was upregulated during OLG differentiation. Biochemical analysis revealed increased activity of metalloproteinases responsible for cleaving galectin-3 during OLG differentiation and modulating its biological activity. Exposure to galectin-3 promoted OLG differentiation in a dose- and carbohydrate-dependent fashion consistent with the 'glycosylation signature' of immature versus differentiated OLG. Accordingly, conditioned media from galectin-3-expressing, but not galectin-3-deficient ( $L$ gals $3^{-1-}$ ) microglia, successfully promoted OLG differentiation. Supporting these findings, morphometric analysis showed a significant decrease in the frequency of myelinated axons, myelin turns (lamellae) and g-ratio in the corpus callosum and striatum of $L$ gals $3^{-/-}$compared with wildtype (WT) mice. Moreover, the myelin structure was loosely wrapped around the axons and less smooth in $\mathrm{Lgals}^{-/-}$mice versus WT mice. Behavior analysis revealed decreased anxiety in $L g a l s 3^{-1-}$ mice similar to that observed during early demyelination induced by cuprizone intoxication. Finally, commitment toward the oligodendroglial fate was favored in neurospheres isolated from WT but not $L$ gals $3^{-/-}$mice. Hence, glial-derived galectin-3, but not galectin-1, promotes OLG differentiation, thus contributing to myelin integrity and function with critical implications in the recovery of inflammatory demyelinating disorders.

Cell Death and Differentiation (2011) 18, 1746-1756; doi:10.1038/cdd.2011.40; published online 13 May 2011

Oligodendrocytes (OLGs) are myelin-producing cells of the central nervous system (CNS) whose function is critical at the interface of neuronal and immune cell processes. ${ }^{1}$ OLG precursors are characterized by their reactivity to A2B5 and O4 monoclonal antibodies. ${ }^{2}$ These cells develop into young oligodendroglial multipolar cells that react with both $\mathrm{O} 4$ and $\mathrm{O} 1$ antibodies. When these cells mature into fully differentiated OLG, they express the enzyme 2', $3^{\prime}$-cyclic nucleotide phosphodiesterase (CNPase) as well as myelin basic protein (MBP) and myelin proteolipid protein (PLP).

Galectins, a family of $\beta$-galactoside-binding lectins, can form multivalent complexes with cell surface glycoconjugates and deliver intracellular signals to modulate cell differentiation and survival. ${ }^{3}$ Recent efforts involving genetic or biochemical manipulation of $\mathrm{N}$ - and $\mathrm{O}$-glycosylation pathways, as well as disruption of endogenous galectins, have illuminated essential roles for galectin-glycoprotein lattices in the control of different biological processes. Although galectins do not appear to have specific individual receptors, they bind to a set of cell surface or extracellular matrix glycoconjugates containing suitable oligosaccharides. ${ }^{4}$ Within the immune system, galectin-1 and -3 often have antagonistic roles in the regulation of adaptive immunity. ${ }^{5}$ Although galectin-3 has predominant proinflammatory roles, galectin-1 has antiinflammatory activities. ${ }^{5}$ We found that galectin-1-deficient mice are considerably more susceptible to Th1- and Th17mediated demyelinating disease. ${ }^{6,7}$ In contrast, galectin-3 deficiency results in reduced severity of experimental autoimmune encephalomyelitis (EAE). ${ }^{8}$

Interestingly, galectin-3 is upregulated in spinal cords and optic nerves of mice with $\mathrm{EAE},{ }^{9}$ suggesting its potential role in modulating neuroimmune processes. Remarkably, galectin-1 promotes axonal regeneration, ${ }^{10}$ stimulates proliferation of neural stem cells (NSCs) in the adult brain, ${ }^{11}$ and accelerates degeneration of neuronal processes under certain circumstances. ${ }^{12}$ On the other hand, galectin-3 stimulates neural cell adhesion and neurite growth, ${ }^{13}$ whereas inhibits Schwann cell proliferation in cultured sciatic nerve. ${ }^{14}$ Within the glial

\footnotetext{
${ }_{1}^{1}$ Department of Biological Chemistry, IQUIFIB, FFyB, UBA-CONICET, Bs As, Argentina; ' ${ }^{2}$ aboratory of Immunopathology, IBYME/CONICET, C1428 Bs As, Argentina; ${ }^{3}$ Department of Dermatology, UC Davis School of Medicine, Sacramento, CA, USA and ${ }^{4}$ Department of Biological Chemistry, FCEN, UBA, C1428 Bs As, Argentina *Corresponding author: JM Pasquini, Dpto de Qca Biol, FFyB-UBA- Junín 956, C1113 Bs As, Argentina. Tel: + 54114964 8287/88; Fax: + 54 11 4962 5457; E-mail: jpasquin@qb.ffyb.uba.ar

${ }^{5}$ These authors contributed equally to this work.

Keywords: galectins; galectin-3; oligodendrocyte; differentiation; myelination

Abbreviations: CNS, central nervous system; OLGs, oligodendrocytes; Lgals3 ${ }^{-/-}$, galectin-3 deficient; WT, wild type; CNPase, 2', 3'-cyclic nucleotide phosphodiesterase; MBP, myelin basic protein; PLP, myelin proteolipid protein; EAE, experimental autoimmune encephalomyelitis; BDNF, brain-derived neurotrophic factor; GDM, glial-defined medium; MMP, metalloproteinase; PNA, peanut agglutinin; SNA, Sambuccus nigra agglutinin; MAL II, Maackia amurensis agglutinin; CC, corpus callosum; CG, cingulum; SVZ, subventricular zone; NSCs, neural stem cells

Received 04.8.10; revised 01.3.11; accepted 09.3.11; Edited by G Melino; published online 13.5.11
} 
compartment, galectin-1 induces astrocyte differentiation, which leads to the production of brain-derived neurotrophic factor, ${ }^{15}$ whereas galectin-3 promotes scavenger receptormediated myelin phagocytosis. ${ }^{16}$ Yet, the relevance of galectin-glycan lattices in OLG physiology is uncertain. Here, we identified an essential role for galectin-glycan interactions in regulating OLG differentiation leading to the control of myelin integrity and function.

\section{Results}

For in vitro experiments we used two different systems: (a) primary OLG cultures ${ }^{17}$ and (b) the OLG line N20.1 $1^{18}$ at two different stages of differentiation. Purified OLG were maintained in glial-defined medium (GDM) supplemented with PDGFAA and bFGF for $48 \mathrm{~h}^{19}$ These progenitor cells were called oligodendroglial progenitor cells (OPCs). A second group was allowed to differentiate for $48 \mathrm{~h}$ in GDM in the absence of growth factors and designated as oligodendroglial differentiated cells (ODCs). N20.1 is a thermosensitive cell line that proliferates at $34^{\circ} \mathrm{C}$ and differentiates at $39^{\circ} \mathrm{C}$.

Regulation of galectin-1 and -3 during OLG differentiation. N20.1 cell lines showed high expression of galectin-1 both in undifferentiated $\left(34^{\circ} \mathrm{C}\right)$ and differentiated $\left(39^{\circ} \mathrm{C}\right)$ states (Figure 1a), whereas OPCs and ODCs showed very weak expression of this protein (Figure 1a). These differences are in line with the well-established role of galectin-1 in cellular transformation. ${ }^{20}$ As N20.1 cell lines were obtained by an immortalization procedure, OPCs and ODCs represent a more physiological developmental model. Given that cell lysates of OLG cultures contain around $5-10 \%$ of non-OLG, particularly astrocytes and microglia, the scarce immunoreactivity observed could be due to cells belonging to other cell lineages. Using markers specific of

a

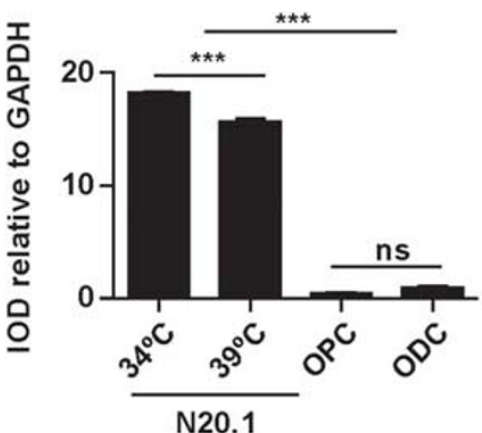

b

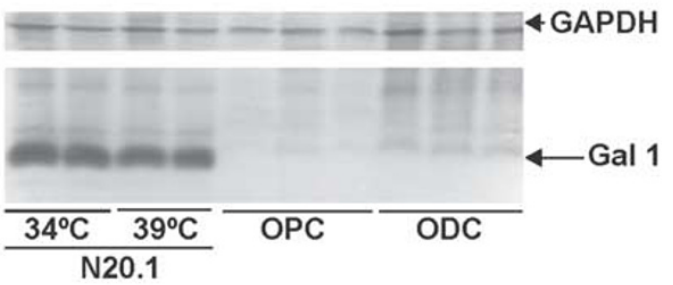

N20.1
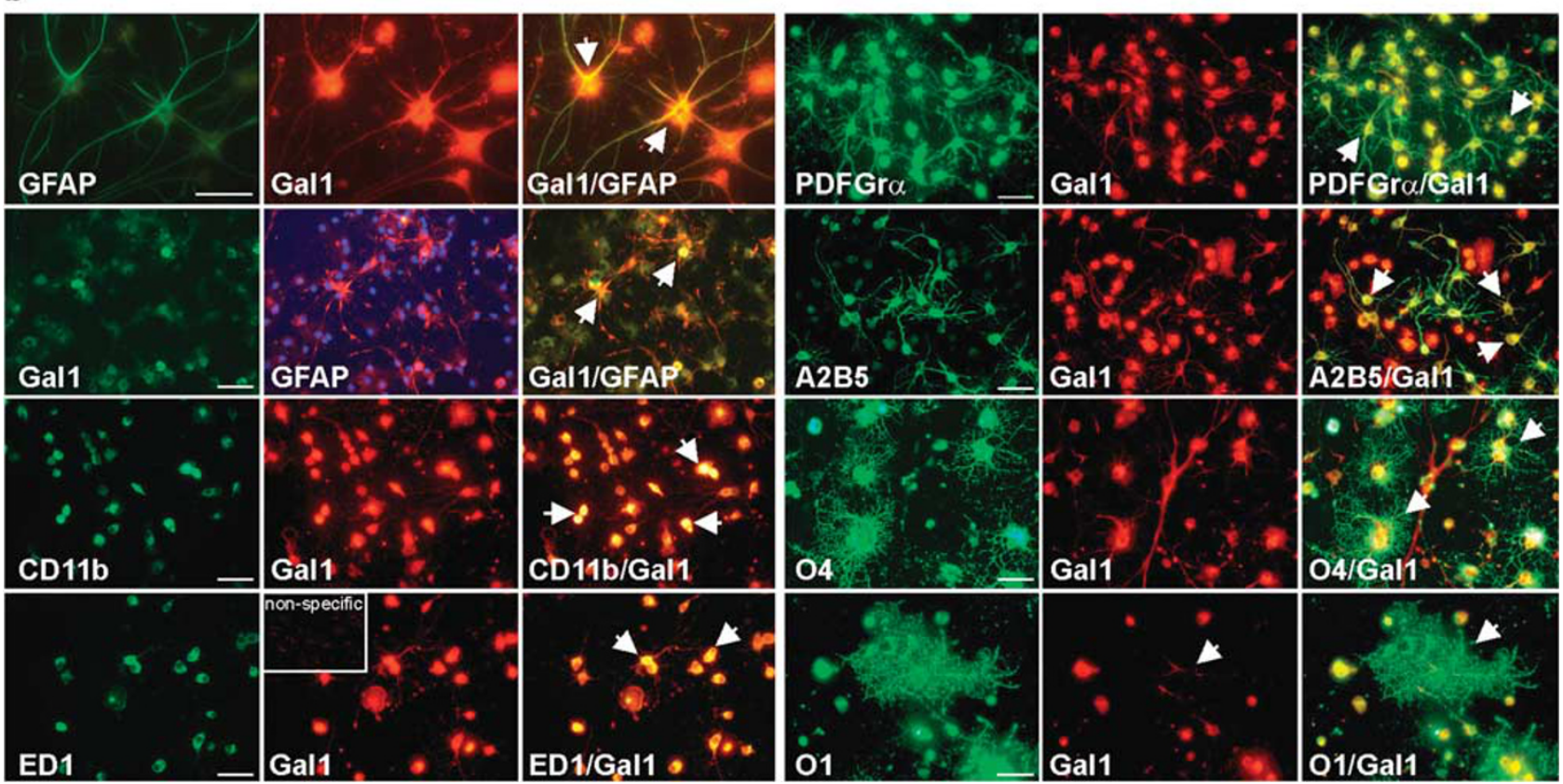

Figure 1 Regulated expression and cellular distribution of galectin-1 in N20.1 cells, astrocytes, microglia and primary OLG cultures at different stages of differentiation. (a) Western blot analysis shows high expression of galectin-1 in N20.1 cell lines in contrast to the weak levels observed in OPCs and ODCs. Data are expressed as IOD (integral optical density) normalized to GAPDH as the means \pm S.E.M. of three independent experiments using three different primary cultures obtained from different rats. Data were analyzed by one-way analysis of variance (ANOVA) followed by Bonferroni post-hoc tests $\left.{ }^{* * *} P<0.001\right)$. (b) Immunocytochemical analysis showed co-localization

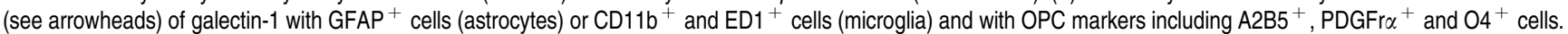
ODCs, identified as $01^{+}$cells, were not found to be galectin-1 ${ }^{+}$. Gal1, galectin-1; ODCs: differentiated OLGs; OPCs, undifferentiated OLGs. Scale bar, $8.2 \mu \mathrm{m}$ 
a
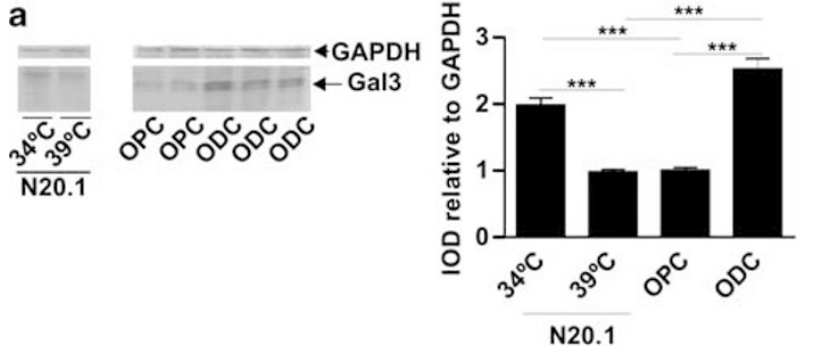
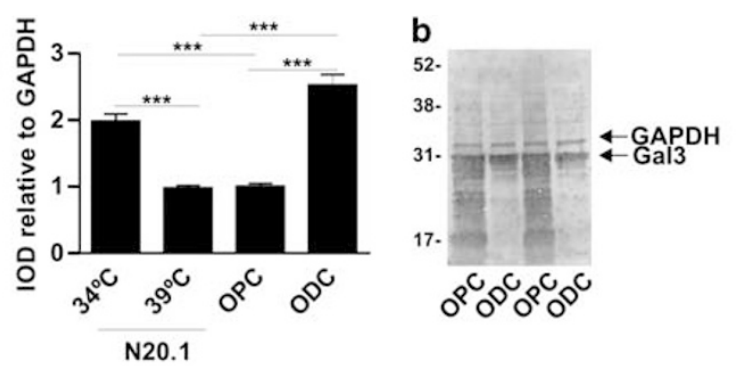

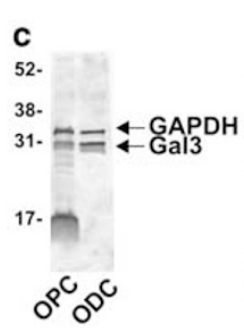

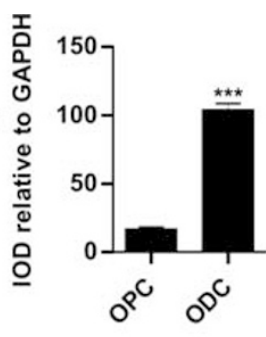

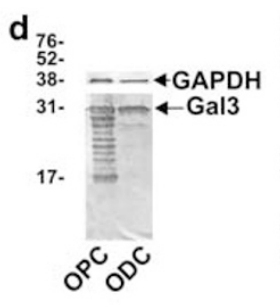

f

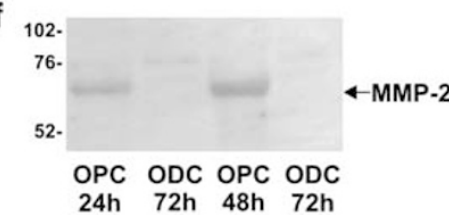

e

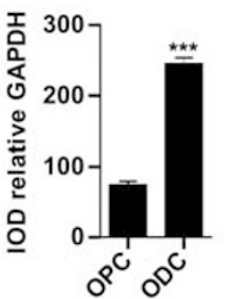

$64 \mathrm{kDa}$
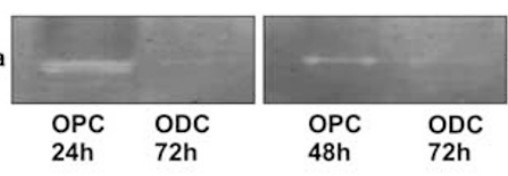

g

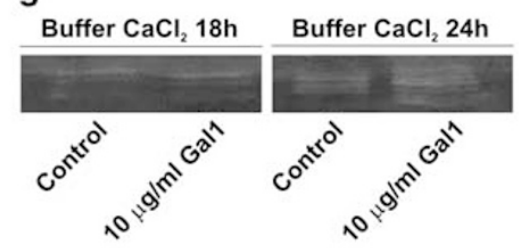

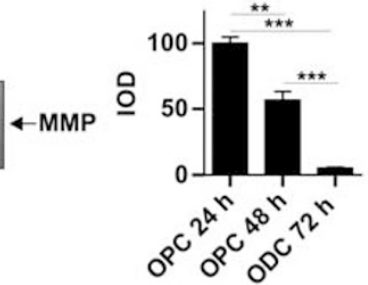

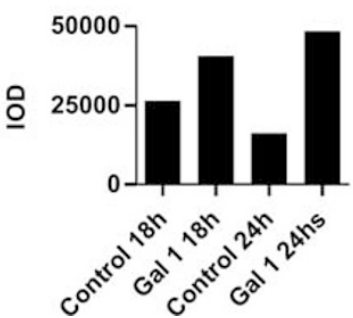

Figure 2 (a-d) Regulated expression and cellular distribution of galectin-3 during OLG differentiation. (a) Cytosolic fraction of N20.1 cells and primary OLG obtained at different stages of differentiation were analyzed on 15\% SDS-PAGE. (b) OPCs and ODCs were lysed in TOTEX buffer and separated on 12.5\% SDS-PAGE. (c and d) OPCs and ODCs were lysed in RIPA buffer and separated on $12.5 \%$ (c) or $15 \%$ (d) SDS-PAGE. Degradation products of galectin-3 are shown as low-molecular-weight bands specifically immunoreactive with the galectin-3 antibody. N20.1 cells showed weak expression of galectin-3 as compared with ODCs. A significant upregulation of galectin-3 was observed in ODCs versus OPCs. Values are expressed as IOD of the 31-kDa band normalized to GAPDH as the mean \pm S.E.M. of three independent experiments using three different primary cultures obtained from different rats. Comparisons were performed using one-way analysis of variance (ANOVA) followed by Bonferroni post-hoc tests in a and unpaired one-tailed Student's $t$-test in $\mathbf{c}$ and $\mathbf{d}{ }^{* \star} P<0.01$ and $\left.{ }^{* \star *} P<0.001\right)$. (e) Changes in proteinase activity during OLGc differentiation were analyzed by gelatinolytic zymography. Clear areas represent proteolytic activity evaluated in OPCs conditioned media (obtained from 24- or 48-h cultures) versus conditioned media from ODCs. Values are expressed as IOD normalized to the mean \pm S.E.M. of three independent experiments. Comparisons were performed using one-way analysis of variance (ANOVA) followed by Bonferroni post-hoc tests. Results show a significant decrease in the proteolytic activity localized to a 64-kDa protein band during OLG differentiation. (f) Western blot analysis for MMP-2 using a specific MMP-2 antibody. A band at $64 \mathrm{kDa}$ was detected only in OPC-conditioned media in three independent experiments. (g) Proteolytic activity was evaluated in OPC-conditioned media obtained from 48-h cultures in the presence or absence of recombinant galectin-1. Gels were incubated for 18 or $24 \mathrm{~h}$ in $\mathrm{CaCl}_{2} 5 \mathrm{mM}$ to reactivate enzyme activity. Quantification IOD shows values corresponding to only the experiment showed in the zymography, but an up-regulation of $55 \pm 11 \%$ in proteolytic activity was observed in OPCs treated with recombinant galectin-1 as the mean \pm S.E.M. of three independent experiments ( $\left.{ }^{\star *} P<0.01\right)$. Gal1, galectin-1; Gal3, galectin-3

different cell types and/or distinct differentiation stages, we identified galectin-1 in astrocytes $\left(\mathrm{GFAP}^{+}\right)$, microglia $\left(\mathrm{CD} 11 \mathrm{~b}^{+}\right.$and $\left.\mathrm{ED} 1^{+}\right)$and immature OLG (A2B5 ${ }^{+}$, PDGFr $\alpha^{+}$and $\mathrm{O}^{+}$cells). However, $\mathrm{O}^{+}$cells were not positive for galectin-1 (Figure $1 \mathrm{~b}$ and Supplementary Figure 1AS). Remarkably, $83.8 \%$ of cells coexpressed PDGFr $\alpha$ and galectin-1 when assessed by flow cytometry (Supplementary Figure 1BS).

In contrast to galectin-1, expression of galectin-3 was very low in undifferentiated and in differentiated N20.1 with a slightly higher molecular weight compared with that observed in primary cultures (Figure 2a). In primary OLG cultures, considerable upregulation of galectin-3 was observed during OLG differentiation. This regulated expression was apparent when total cell lysates as well as the cytosolic fraction of OLG were examined (Figures 2a-d). Strikingly, when total cell lysates of OPCs were analyzed by different schedules, a number of specific bands of lower molecular weight also immunoreacted with the anti-galectin-3 antibody (Figures $2 b-d)$. As these results were only obtained when we used total cell extracts, we hypothesized that this lectin could be extracellularly degraded in immature OPCs and further stabilized in ODCs, suggesting variations in the biological activity of galectin-3 during OLG differentiation. Ochieng et al. ${ }^{21}$ showed that galectin-3 is readily cleaved by matrix metalloproteinases (MMPs), thus altering its carbohydratebinding activity. These observations prompted us to investigate whether changes in MMP activity promote galectin-3 degradation during OLG differentiation. The activity of MMPs in conditioned medium of 24 and $48 \mathrm{~h}$-cultured OPCs and $72 \mathrm{~h}$-cultured ODCs was substantially decreased in differentiated OLG (Figure 2e). As galectin-3 has been reported to be a substrate for MMP-2 and $-9,{ }^{21}$ and our MMP activity was detected in a $64 \mathrm{kDa}$ band, we investigated the identity of this 


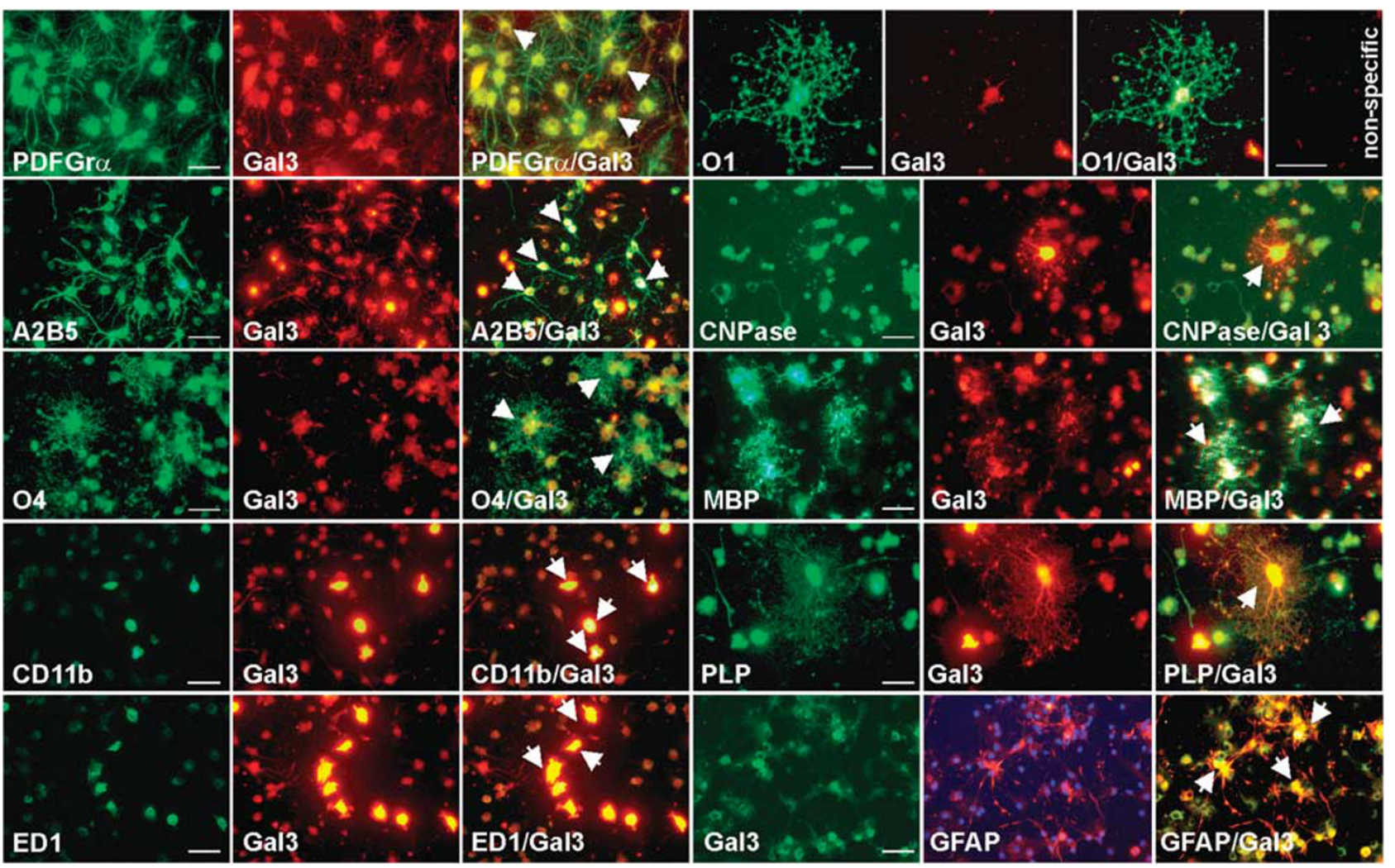

Figure 3 Expression of galectin-3 in different glial cell populations. Immunocytochemical analysis reveals co-localization of galectin-3 (see arrowheads) with OPCs

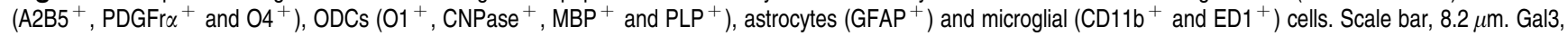
galectin-3

protein using a specific antibody. Our results showed a high MMP-2 immunoreactivity only in conditioned medium of 24 and $48 \mathrm{~h}$-cultured OPCs (Figure 2f). Given the ability of galectin- 1 to upregulate MMP expression, ${ }^{22}$ and its selective expression in undifferentiated cells (Figure 1a), we analyzed MMP activity in conditioned medium from immature OLG treated or not with recombinant galectin-1. Our results showed upregulation of $55 \pm 11 \%$ in MMP activity of immature OLG treated with recombinant galectin-1 (Figure $2 \mathrm{~g}$ ), suggesting a dynamic interplay between galectin-1 and galectin-3 in the regulation of OLG differentiation.

To understand the physiologic relevance of galectin-3 within glial cells, we evaluated its differential expression. Galectin-3 was expressed in immature (PDGFra ${ }^{+}, \mathrm{A}^{2} \mathrm{~B}^{+}$ and $\left.\mathrm{O}^{+}\right)$and mature $\left(\mathrm{O}^{+}, \mathrm{MBP}^{+}, \mathrm{CNPase}^{+}, \mathrm{PLP}^{+}\right.$) OLGs, as well as in astrocytes (GFAP ${ }^{+}$cells) and microglial cells $\left(\mathrm{CD} 11 \mathrm{~b}^{+}, \mathrm{ED}^{+}\right)$(Figure 3$)$. These results were confirmed by flow cytometry showing $47.1 \%$ of cells coexpressing galectin-3 and GFAP, $80.8 \%$ of cells coexpressing galectin-3 and PDGFr $\alpha$ (a marker of OPCs that appears before A2B5 immunoreactivity), $61.7 \%$ of cells coexpressing galectin-3 and 04 , and $75.1 \%$ of cells coexpressing galectin-3 and $\mathrm{O} 1$ (Supplementary Figures $1 \mathrm{AS}$ and BS).

To examine whether endogenous galectin-3 affects OLG differentiation, we overexpressed galectin-3 in the N20.1 cell line and evaluated MBP promoter activity using a luciferase reporter as an OLG differentiation parameter. Overexpression was confirmed by analyzing the levels of galectin-3 in N20.1 cell lysates (Figure 4a). No changes were observed in MBP promoter activity, suggesting that fluctuations in the relative abundance of endogenous galectin-3 do not affect OLG differentiation (Figures $4 \mathrm{~b}$ and $\mathrm{c}$ ).

\section{Galectin-3-glycan interactions drive OLG} differentiation. To determine whether galectin-glycan lattices mediate the cross-talk among different glial cells, we studied the capacity of microglial cells to regulate OLG differentiation via secretion of galectin-3. When OPCs were differentiated in the presence of microglia-conditioned GDM, isolated from galectin-3-deficient $\left(\mathrm{Lgals}^{-/}\right)$or wild-type (WT) mice, these cells experienced a considerable decrease in the frequency of $\mathrm{MBP}^{+}$cells in OLG exposed to GDM from Lgals $^{-1-}$ versus WT microglia (Figure 5a).

To further investigate the functional relevance of galectins during OLG differentiation, we profiled the cell surface 'glycosylation signature' of OLG at different stages of differentiation. Remarkably, OPCs expressed the repertoire of glycan-binding sites required for galectin recognition and function. This was reflected by the high reactivity of these cells with PNA, a plant lectin that recognizes asialo-core-1-Oglycans (Figure $5 \mathrm{~b}$ ). These glycan structures are substrates of the core $2 \beta 1,6-N$-acetylglucosaminyltransferase that is responsible for generating complex core 2-O-glycans, which are preferred ligands of galectins. ${ }^{5}$ In addition, we found 


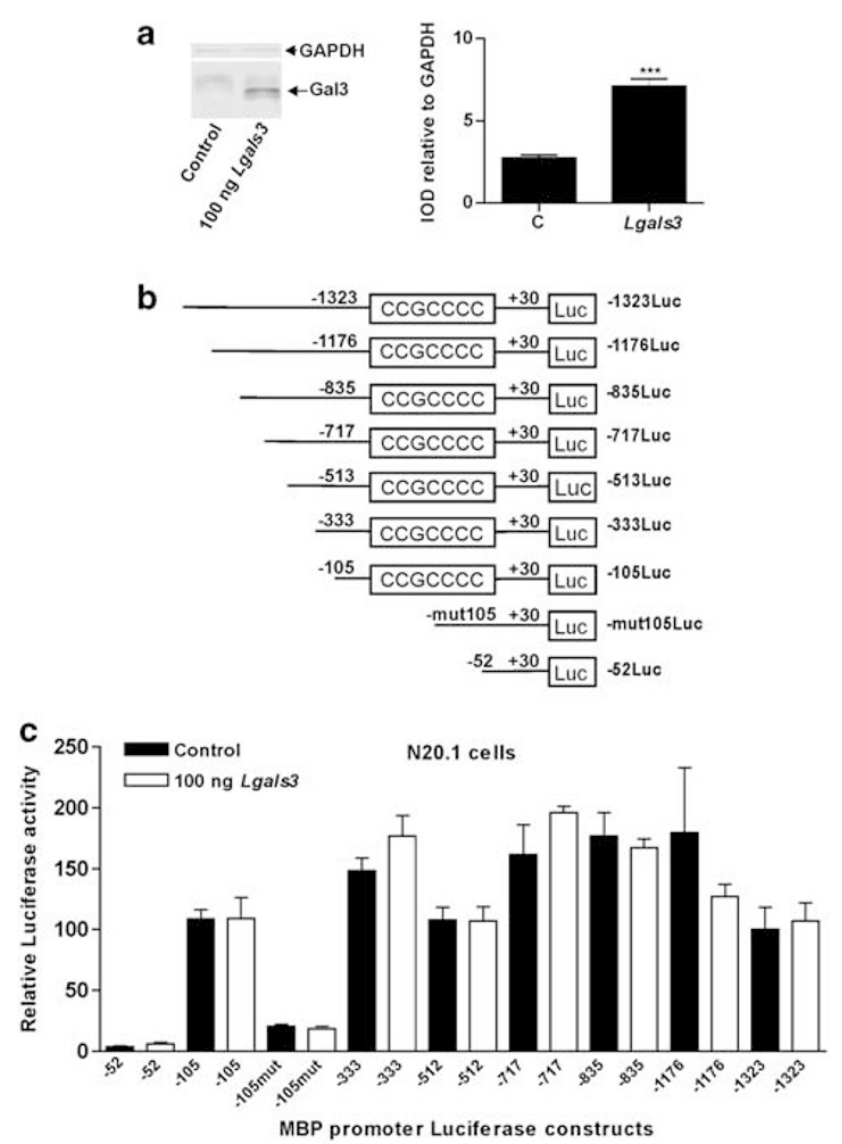

Figure 4 MBP promoter activity in N20.1 oligodendroglial cell lines overexpressing galectin-3. (a) Over-expression was checked by analyzing the levels of galectin-3 in lysed N20.1 cells transfected with $100 \mathrm{ng}$ of galectin-3 plasmid or empty vector by western blot. Values are expressed as IOD normalized to the mean \pm S.E.M. of three independent experiments. Comparisons were performed using unpaired one-tailed Student's $t$-test ${ }^{\star \star \star} P<0.001$. Results show a significant increase in galectin-3 in transfected cell lines. (c) N20.1 cells were transfected with different galectin-3 plasmid concentrations (25,50, 100 and $200 \mathrm{ng})$ and distinct constructs of the MBP promoter schematized in $\mathbf{b}$. Neither of the different portions of the MBP promoter was capable of inducing fluctuations at the plasmid concentrations used (c). Only the $100 \mathrm{ng}$ galectin-3 plasmid concentration is shown. Gal3, galectin-3

intermediate reactivity of the Sambuccus nigra agglutinin (SNA), a plant lectin that recognizes terminal $\alpha 2-6$ sialic acid attached to galactose, and intermediate binding of Maackia amurensis agglutinin (MAL II), which recognizes $\alpha 2-3$ sialic acid linked to $\mathrm{N}$-glycans. Importantly, this 'permissive glycosylation signature' was substantially altered in ODCs, which showed a PNA ${ }^{\text {low }}, S N A^{\text {int }}$ and MAA ${ }^{\text {int }}$ glycophenotype (Figure $5 b$ ). This profile was in complete agreement with the increased binding of galectins to the surface of OPCs versus ODCs.

Given the availability of galectin ligands and the effects of microglial culture medium in OLG differentiation, we next investigated the influence of exogenous galectins in OLG primary cultures. As cell viability was significantly affected at concentrations starting from $20 \mu \mathrm{g} / \mathrm{ml}$ of galectin-3 (Figure 5c), we selected 5 and $10 \mu \mathrm{g} / \mathrm{ml}$ as working concentrations. Treatment of OPCs with recombinant galectin-3 increased the frequency of $\mathrm{O}^{+}$and $\mathrm{MBP}^{+}$cells and reduced the number of $\mathrm{A}_{2} \mathrm{~B} 5{ }^{+}$cells, whereas induced no changes in the number of $\mathrm{GFAP}^{+}$cells (Figures $5 d-f$ ), indicating that galectin-3 drives OLG differentiation without exerting substantial effects on astrocytes. Remarkably, arborization of $\mathrm{MBP}^{+}$cells was substantially higher in galectin-3-treated cells compared with untreated cells (Figure $5 \mathrm{~g}$ ). A substantial increase in the expression of all MBP isoforms was observed in cells treated for 48 and $72 \mathrm{~h}$ with recombinant galectin-3 (Figure $5 \mathrm{~h}$ ). In contrast, exposure to galectin-1 at equivalent concentrations resulted in a considerable inhibition of OLG differentiation, as shown by diminished expression of different MBP isoforms at 48 and $72 \mathrm{~h}$ of incubation (Figure 3i). This result was not was due to decreased cell viability induced by galectin-1 (Figure 3j). Hence, galectin- 1 and -3 exert contrasting effects during the process of OLG differentiation.

Endogenous galectin-3 controls myelin integrity and function in vivo. Given the stimulatory effects of galectin-3 in OLG differentiation in vitro, we next investigated the in vivo role of this protein during the myelination process. Galectin-3 expression was analyzed by western blot and immunohistochemistry during normal myelination at postnatal day 5 (P5), 10 (P10), 15 (P15) and 20 (P20). A transgenic mice expressing EGFP driven by the CNPase promoter (CNP-EGFP) was used for these experiments. ${ }^{23}$ These mice were useful for evaluating galectin-3 expression in all oligodendroglial lineages (CNPase ${ }^{+}$cells) as well as in neighboring cells. We found substantial changes in galectin-3 expression as a function of age mainly affecting areas of white matter development. Western blot analysis was performed in total cell lysates of a dissected area corresponding to corpus callosum (CC) (Supplementary Figure 2AS, dotted line). Results showed a high level galectin-3 expression at P5, which decreased upon myelin development (Supplementary Figure 2BS). In agreement, we found high levels of galectin-3 in microglial $\left(C D 11 b^{+}\right)$cells localized in the $C C$ and cingulum tightly close to CNPase ${ }^{+}$ cells at P5 (Supplementary Figure 2CS). Interestingly, some $\mathrm{CNPase}^{+}$cells with morphology of mature OLGs were found to colocalize with galectin-3 by confocal microscopy. On the other hand, at P10 and P15, galectin-3 was present at low levels in $\mathrm{GFAP}^{+}$astrocytes. Moreover, we observed a high galectin-3 immunostaining in the subventricular zone (SVZ) at all ages studied (Supplementary Figure 2DS). Colocalization studies showed that these cells were galectin $-3^{+} /$ $\mathrm{GFAP}^{-}$, indicating that they were not astrocytes-like type B cells. As these cells were in the lining of the lumen of ventricles, they were likely to be ependymal cells. When we analyzed MBP and RIP expression, we found a decreased immunoreactivity of both markers in the $C C$ in 4- and 8-weekold Lgals $3^{-1}$ versus WT mice (Supplementary Figure 3A-DS). A considerably reduced staining in myelinated tracts was also observed by eryochrome cyanine staining, a specific lipid dye, in Lgals3 ${ }^{-1}$ versus WT mice (Supplementary Figure 3GS). These results were confirmed by a significant decrease in MBP isoforms in CC and striatum (St) of Lgals3 $^{-1-}$ versus WT mice (Supplementary Figures 3B-DS). In agreement with in vitro data, the presence of galectin-3 did 

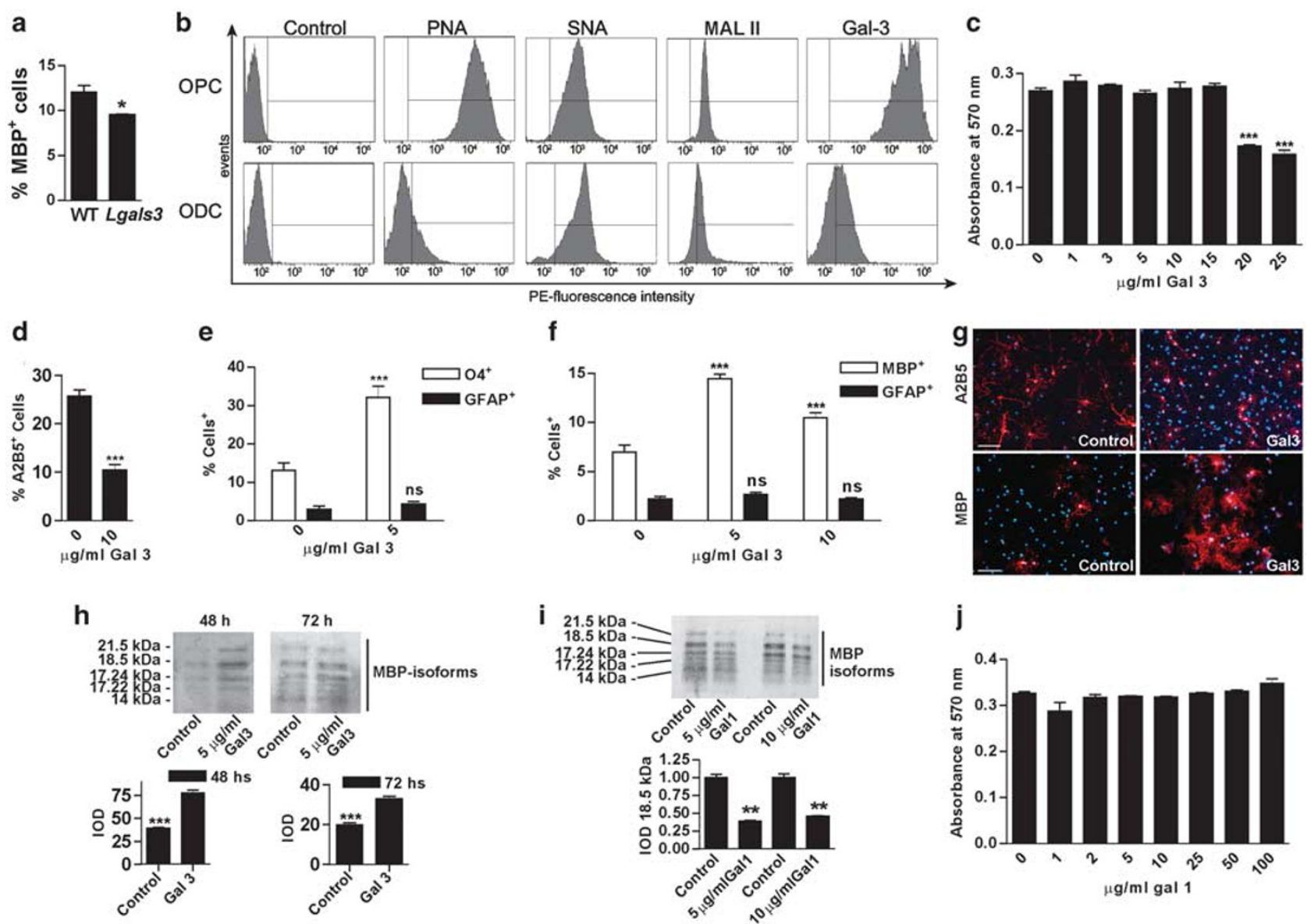

Figure 5 Binding and function of extracellular galectin-3 to OLGs. (a) Evaluation of MBP ${ }^{+}$cells in OPCs exposed to conditioned media from $\mathrm{Lgals}^{-/-}$or WT mice microglial cells. Values are expressed as the mean \pm S.E.M. of three independent experiments using three different primary cultures obtained from different animals $\left({ }^{\star} P<0.05\right)$. Immunocytochemical studies indicate a significant increase in the number of MBP ${ }^{+}$cells when OPCs were differentiated in the presence of WT versus galectin-3deficient microglia conditioned. (b) Differential glycophenotype and binding of galectin-3 to the surface of OPCs and ODCs. Expression of cell surface oligosaccharides on OPCs and ODCs detected with biotinylated lectins including SNA, MAL II and PNA. Control includes cells stained with streptavidin alone. Biotinylated galectin-3 was used to detect binding of galectin-3 to the surface of OPCs and ODCs. Binding was mediated by lectin-glycan interactions as demonstrated by competition with $30 \mathrm{mM}$ lactose but not $30 \mathrm{mM}$ sucrose (data not shown). Data are representative of three independent experiments. (c-g) Effect of recombinant galectin-3 on cell viability and OLG differentiation. OPCs cultured in the absence or presence of different concentrations of recombinant galectin-3. (c) Cell viability, evaluated by the MTT assay. Values are expressed as the mean \pm S.E.M. of three independent experiments. Results show a significant decrease in the cell viability starting from $20 \mu \mathrm{g} / \mathrm{ml}$ of galectin-3 $\left.{ }^{* \star *} P<0.001\right)$. (d-f) A2B5 ${ }^{+}$, $\mathrm{O}^{+}, \mathrm{MBP}^{+}$and $\mathrm{GFAP}^{+}$cells were evaluated in primary oligodendroglial cultures by immunocytochemical analysis. Treatment with recombinant galectin-3 induces a significant decrease in the number of $\mathrm{A}_{2} \mathrm{B5}^{+}$cells concomitant with an increase in $\mathrm{O4}^{+}$and $\mathrm{MBP}^{+}$cells without changes in the number of $\mathrm{GFAP}^{+}$cells. Values are expressed as the mean \pm S.E.M. of three independent experiments $\left({ }^{\star \star \star} P<0.001\right)$. (g) A representative field showing A2B5 ${ }^{+}$and MBP ${ }^{+}$cells is shown. A higher arborization is observed in galectin-3-treated cells. Scale bar, $12.5 \mu \mathrm{m}$. (h) Western blot analysis shows a significant increase of different MBP isoforms in OLG treated with recombinant galectin-3 for 48 or $72 \mathrm{~h}$. Values are expressed as IOD and are the mean \pm S.E.M. of three independent experiments $\left({ }^{* \star *} P<0.001\right)$. (i and j) Effects of recombinant galectin-1 on the differentiation and viability of OLGs. OPCs cultured in the presence of different concentrations of recombinant galectin-1. (i) Cell viability, assessed by the MTT assay, was not affected by any of the concentrations tested. (j) Western blot analysis shows a significant decrease in different MBP isoforms in OLG treated with recombinant galectin1 for $72 \mathrm{~h}$ at both concentrations selected. Values are expressed as IOD and are the mean \pm S.E.M. of three independent experiments $\left({ }^{* *} P<0.01\right)$. Comparisons were performed using unpaired one-tailed Student's $t$-test in $\mathbf{a}, \mathbf{d}, \mathbf{e}, \mathbf{h}$ and $\mathbf{i}$, and one-way analysis of variance (ANOVA) followed by Bonferroni post-hoc tests in $\mathbf{c}, \mathbf{f}$ and $\mathbf{j}$. Gal1, galectin-1; Gal3, galectin-3

not affect the number of $\mathrm{GFAP}^{+}$cells (Supplementary Figures $3 E S$ and FS).

To analyze the myelination process, we studied the ultrastructural morphology of myelin isolated from 4- and 8-week-old mice. Morphometric analysis showed a significant decrease in the percentage of myelinated axons, myelin turns (lamellae) and g-ratio in the St of 4-week-old Lgals3 $^{-1-}$ compared with WT mice. Moreover, in the $C C$, only a slight but significant difference in the percentage of myelinated axons was observed without changes in myelin turns and g-ratio in 4-week-old mice (Figures 6a and b). In contrast, in 8-week mice, a significant decrease in the percentage of myelinated axons, myelin turns and g-ratio were observed in both $S t$ and CC of Lgals $^{-1-}$ mice versus WT littermates (Figures 6a and b). Moreover, the nature of myelin present in $C C$ and St of Lgals $^{-1-}$ mice was loosely wrapped around the axons and less smooth when compared with the myelin obtained from WT mice. This finding suggests altered myelin integrity and abnormal compaction in mice lacking galectin-3. This altered myelin structure was observed by the splitting of the 

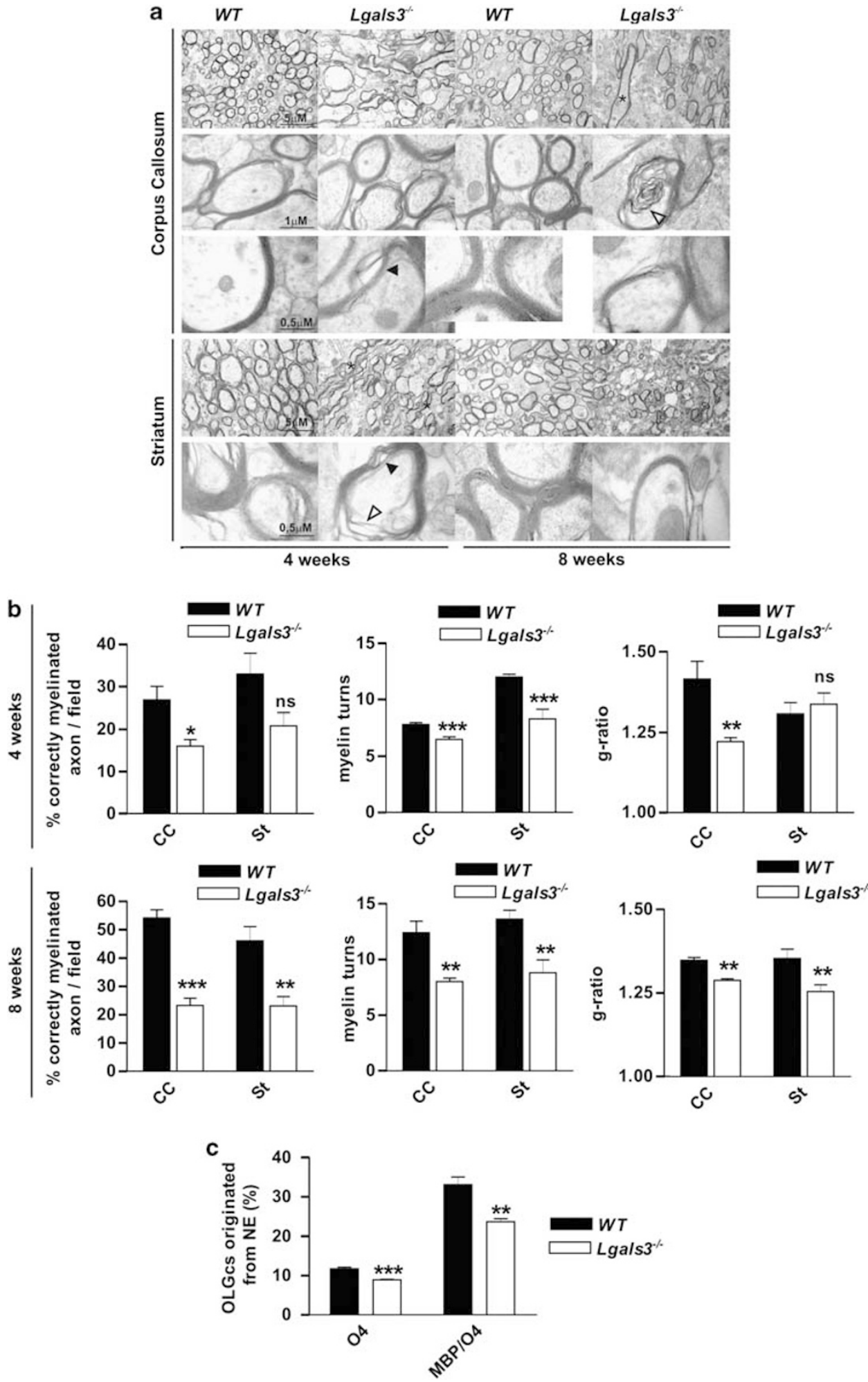

Figure 6 (a) Electron microscopy studies of myelin in CC or St from 4- or 8-weeks-old $\mathrm{Lgals}^{-/-}$and WT mice. (a) Representative fields of electron microscopic analysis of myelin at different magnifications. Myelin obtained from $\mathrm{Lgals}^{-/-}$mice is loosely wrapped around the axons compared with myelin from WT mice (open arrowheads). Altered myelin structure is observed by the splitting of the interperiod lines and separation of the axolemma (black arrowheads). Axons of $\mathrm{Lgals}^{-/-}$mice are found to be collapsed (asterisk). (b) Morphometric analysis shows a decrease in the percentage of correctly myelinated axons, in myelin turns and g-ratio in Lgals $3^{-1-}$ versus WT mice. Values are expressed as the mean \pm S.E.M. of three independent experiments $\left({ }^{\star} P<0.05\right.$, ${ }^{\star \star} P<0.01$ and $\left.{ }^{\star \star *} P<0.001\right)$. (c) Studies of oligodendroglial cell commitment originated from neurospheres obtained from $\mathrm{Lgals}^{-1-}$ and WT mice. Quantitative analysis was performed by flow cytometry, demonstrating enhanced oligodendroglial fate in neurospheres isolated from WT versus $\mathrm{Lgals}^{-1-}$ mice. Values are expressed as the mean \pm S.E.M. of three independent experiments using three different primary cultures obtained from different mice $\left({ }^{*} P<0.05,{ }^{*} P<0.01\right.$ and $\left.{ }^{* * *} P<0.001\right)$. Comparisons were performed using unpaired one-tailed Student's $t$-test 
a

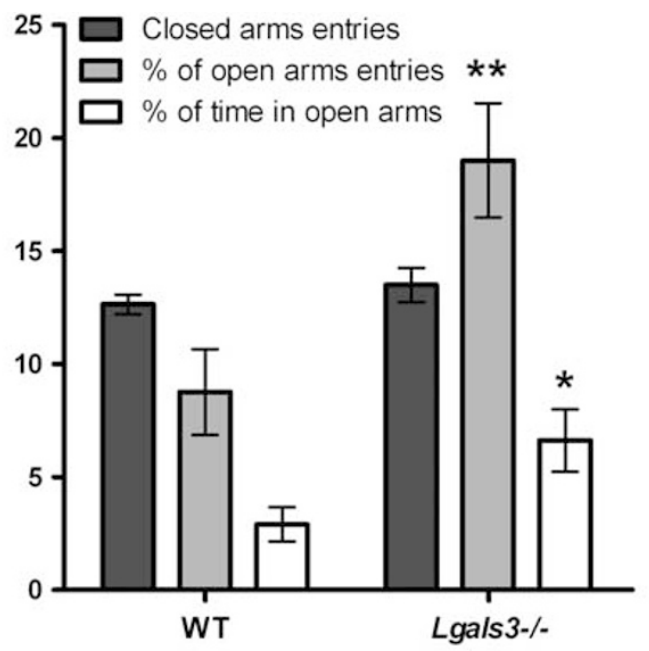

b

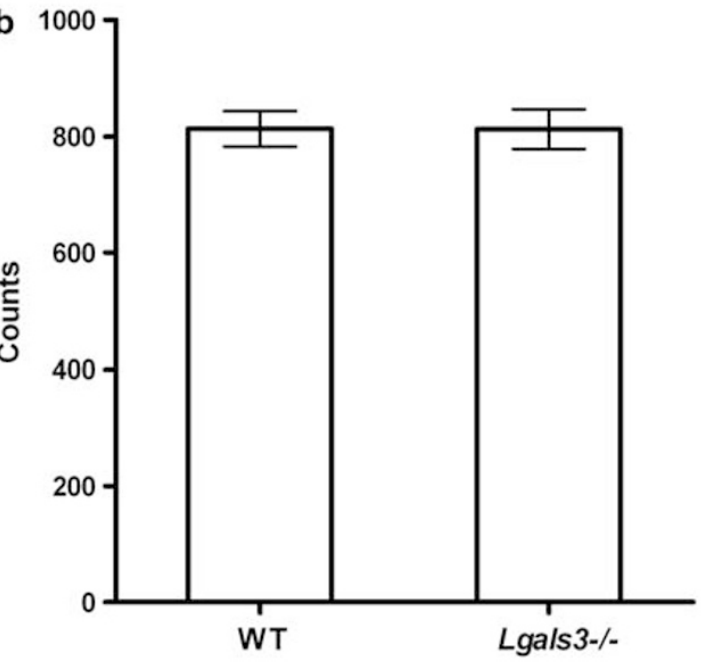

C

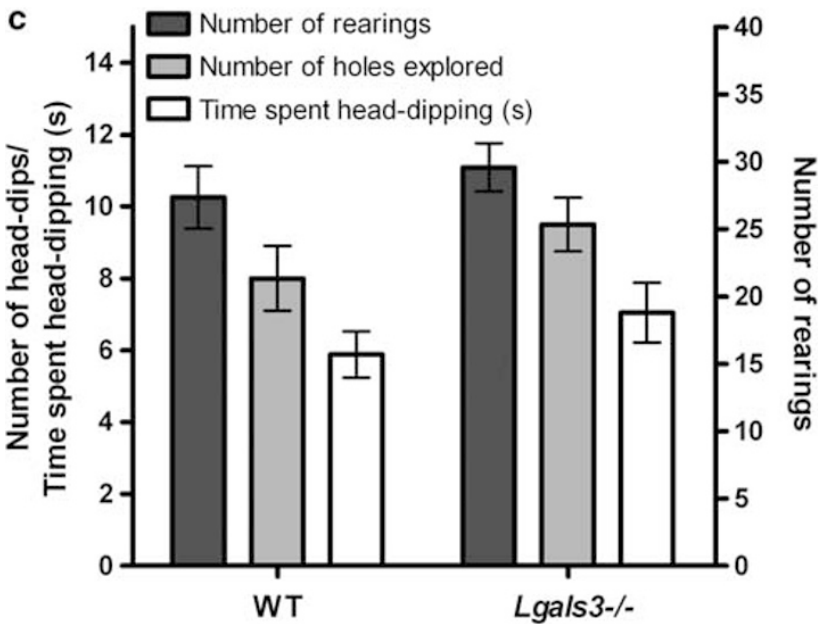

Figure 7 Performance of mice in the plus-maze, locomotor activity and holeboard tests. Results are expressed as mean \pm S.E.M. of (a) closed-arm entries, percentage of open-arm entries and percentage of time spent in open arms measured in the plus-maze test; (b) Locomotor activity counts and (c) the holeboard parameters; registered in 5-min sessions. The symbols denote significance levels: ${ }^{\star} P<0.05$ and ${ }^{* \star} P<0.01$ significantly different from WT mice; unpaired $t$-tests ( $n=14$ and 12 for Lgals3 $^{-1-}$ and WT mice, respectively) interperiod lines and separation of the axolemma in Lgals $^{-/-}$versus WT mice. Furthermore, the axons of Lgals3 $^{-1-}$ mice were found to be collapsed when compared with those from WT littermates (Figure 6a). Thus, galectin3-induced OLG differentiation controls myelin integrity and function.

Finally, using neurospheres ${ }^{24}$ obtained from brains of Lgals3 $^{-/-}$and WT newborns, we examined whether galectin-3 may influence OLG commitment to differentiated cells. Neurospheres were allowed to differentiate for 5 days in GDM to evaluate the number of $\mathrm{O} 4^{+}$or $\mathrm{MBP} / \mathrm{O} 4^{+}$cells. Remarkably, an impaired commitment toward the OLG fate was observed in neurospheres isolated from $\mathrm{Lgals}^{-/-}$versus WT mice (Figure $6 \mathrm{c}$ ), suggesting a critical role of galectin-3 in facilitating OLG fate.

Altered myelin structure in Lgals $^{-/-}$mice leads to behavioral abnormalities. Given the considerable alterations in myelin structure in $\mathrm{Lgals}^{-1-}$ mice, we evaluated possible changes in the behavior of these mutant mice. Results of behavior performance of WT and $\mathrm{Lgals}^{-/}$ mice in the plus-maze, hole-board and locomotor activity tests are shown in Figure 7. In the plus-maze test, Lgals $^{-/-}$ mice significantly increased the percentage of open arm entries $(P<0.01)$ and the percentage of time spent in open arms $(P<0.05)$ as compared with WT mice, whereas the number of closed arm entries were not altered (Figure $7 \mathrm{a}$ ). These data suggest that $\mathrm{Lgals}^{-1-}$ mice have lower levels of innate anxiety than their WT littermates. No other significant differences were found in the parameters analyzed in locomotor activity (Figure 7b), the hole-board (Figure 7c) or the inverted screen tests (data not shown).

\section{Discussion}

Mechanisms that control OLG differentiation are the focus of intensive research at the interface of neurobiology and immunopathology. ${ }^{25,26}$ In the present study, we show that galectin-3 has a critical role in driving OLG differentiation and myelination, whereas galectin-1 is expressed only in OPCs and appears to be an inhibitor of OLG maturation. Our data show that OLG express galectin-3 at different stages of differentiation, although at a lower extent than activated microglia, and demonstrate that galectin-3 has an important role in OLG differentiation. Interestingly, this protein was sensitive to MMP-mediated cleavage in OPCs but not in ODCs, suggesting spatiotemporal changes in its biological activity. Moreover, enhanced OLG maturation was observed in the presence of galectin-3 consistent with a 'permissive glycophenotype' of these cells, whereas no effects were observed when this protein was overexpressed in OLG lines. This result is in agreement with the OLG maturation effects displayed by supernatants derived from galectin-3-expressing but not galectin-3-deficient microglia.

Although galectin-3 was found to be abundantly expressed in activated microglia, ${ }^{9,16}$ this is the first paper, to our knowledge, showing the relevance of galectin-3 in OLG differentiation. Our in vivo studies reinforced the idea that microglial cells and astrocytes can control OLG differentiation during myelination processes through a galectin-3-mediated 
pathway. It has been described that microglia is transiently abundant in the cerebral white matter during the human fetal period, suggesting that these cells may participate in developmental processes including myelination. ${ }^{27}$ The generation of the bulk of OLGs in the white matter coincides with the developmental window during which amoeboid microglia is present in the $C C$. This type of microglia disappears between $\mathrm{P} 10$ and $\mathrm{P}_{14} .^{28}$ The authors suggested that this ameboid microglia may have a role not only in clearing a path for axons, but also in clearing cell debris during gliogenesis. Our results suggest that galectin- 3 may be secreted from microglial cells through an atypical secretory pathway and signals through glycosylated receptors to promote OLG differentiation and maturation. This assumption is supported by our data showing a higher frequency of $\mathrm{MBP}^{+}$cells in the presence of microglial-conditioned medium isolated from WT versus $\mathrm{Lgals3}^{-1}$ mice. At late stages of myelin development, astrocytes could also be the source of galectin-3, which allows these cells to facilitate final OLG differentiation and correct myelin compaction. Yet, we do not rule out possible indirect mechanisms of galectin-3 on OLG differentiation that could involve galectin-3-mediated control of proinflammatory mediators released by microglial cells or changes in the expression of signaling receptors in oligodendroglial cells.

Given the different glycoprophenotype of OPCs versus ODCs, galectin-3 interactions with OLG could be regulated by the repertoire of glycans covering selected glycoproteins and glycolipids. We cannot rule out the possibility that galectin-3 might be secreted from OLG and act in an autocrine fashion to regulate OLG maturation. These findings are supported by the selective cleavage of this protein by MMPs in progenitor but not differentiated OLG. Galectin-3 degradation in immature OLG could be regulating the biological activity of this lectin and control its interactions with cell surface glycoconjugates. Recently, Svedin et al. ${ }^{29}$ have found that under hypoxic ischemia, MMP-2 becomes more prominent in Olig2-positive cells.

Within the CNS, galectin-1 has important functions in the formation of the neural network of the olfactory bulb in mice ${ }^{30}$ and modulates proliferation of neural progenitors in neurogenic regions. ${ }^{31,32}$ Our results show that galentin-3 expression in the SVZ is restricted to ependymal lining in GFAP $^{-}$cells, suggesting that these cells were type $E$ and not type B cells. In contrast, galectin-1 was expressed in a subset of GFAP ${ }^{+}$SVZ astrocytes that includes NSCs. ${ }^{33}$ Here, we showed that galectin-1 is abundant only in PDGFr $\alpha^{+}$and $\mathrm{A}^{2} \mathrm{~B}^{+}{ }^{+}$OPCs, but not in ODCs-expressing markers of more differentiated OLGs $\left(\mathrm{O}^{+}\right.$cells). In contrast to galectin-3, exogenously added galectin-1 induced a significant decrease in OLG differentiation as lower levels of MBP isoforms were observed in total cell lysates of differentiated OLGs. Our observations using recombinant galectins were not due to changes in cell viability, as we carefully selected physiologic concentrations that do not alter OLG survival. Taken together, our results indicate divergent roles of galectin- 1 and galectin-3 in the control of the OLG differentiation. Considerable differences exist in glycan-binding preferences of individual members of the galectin family, ${ }^{6}$ which might explain the functional differences in the biological activities of these proteins. These variations in glycan recognition are mainly associated with the extent of $N$-glycan branching, the multiplicity of LacNAc residues and/or the modification of terminal saccharides (e.g. sialylation). ${ }^{6}$ In our study, examination of the 'glycosylation' signature of OLG revealed considerable differences between OPCs and ODCs. Remarkably, OPCs displayed intermediate levels of $\alpha 2-6$-linked sialic acid, which are permissive for galectin-3 binding, but are more restrictive for galectin-1 recognition. ${ }^{34}$

The critical role of galectin-3 during OLG differentiation is strongly supported by morphological changes observed in myelin of $\mathrm{Lgals3}^{-1-}$ mice. Electron microscopic analysis of mutant mice showed important abnormalities in the myelination process when compared with WT littermates. Morphometric analysis showed hypomyelination of $\mathrm{Lgals3}^{-1-}$ mice in the $S t$ and $C C$, which was more pronounced in 8-week-old compared with 4-week-old mice. The myelin present in $C C$ and St of $\mathrm{Lgals}^{-/-}$mice had a lower integrity with abnormal compaction. Thus, galectin-3 might serve to ensure that myelin is appropriately produced and organized, as has been described earlier for myelin-associated glycoprotein (Siglec-4). ${ }^{35}$ The MAG ectodomain interacts with one or more gangliosides or molecules on the axonal surface similar to galectin-3, which might interact with glycoproteins or glycolipids to favor the myelination process. In this regard, NG2 chondroitin sulfate proteoglycan is a membrane-spanning protein expressed in OPCs and downregulated in ODCs. NG2 can activate endothelial cells and its activity relies on the formation of tri-molecular complexes with integrins and galectin-3. ${ }^{36}$ This could certainly operate as an alternative mechanism by which galectin-3 contributes to OLG differentiation in the CNS. Consistent with abnormalities in myelin structure, $\mathrm{Lgals}^{-/-}$mice exhibited substantial alterations in behavior. The decreased anxiety observed in Lgals3 $^{-1-}$ mice was associated with normal motor coordination in the inverted screen test and no changes in the locomotor activity. Accordingly, Torkildsen et al. ${ }^{37}$ showed that mice given $0.2 \% \mathrm{CPZ}$ undergo a period of hyperactivity and decreased anxiety behavior (after 3 weeks of CPZ administration) before developing motor dysfunction (after 5 weeks).

Our results showed that galectin-3 may assist in the myelination process by promoting OLG differentiation and favoring oligodendroglial commitment following differentiation of NSCs. The contrasting effects of galectin-1 and galectin-3 in OLG differentiation are worthwhile to be discussed in the context of the anti- or proinflammatory effects of these glycanbinding proteins. ${ }^{4}$ Like many cytokines and growth factors, galectins may exhibit a 'double-edge sword' effect depending on many different intrinsic factors, such as the physicochemical properties of the proteins (dimerization or oligomerization status), stability in tissues (relative activity of MMPs), their different concentrations and the redox state of the cells, as well as extrinsic factors, such as the glycosylation status of target cells. ${ }^{3,4}$ In fact, both galectin-1 and galectin-3 share most of the biochemical and functional features of cytokines including upregulated expression in inflammatory and glial cells, as well as autocrine and paracrine actions. Hence, it is attractive to speculate that different biological systems will respond to an exacerbated inflammatory response by increasing the local production of these glycan-binding proteins in an attempt to restore cell homeostasis, suggesting 
their potential use as novel immunomodulatory agents. However, before galectin-based therapeutic strategies can be embraced, a more thorough understanding of the mechanisms involved in galectin functions and their spatiotemporal regulation during neuroinflammation is required.

\section{Materials and Methods}

Materials. Anti-MBP, A2B5, $\mathrm{O} 1$ and $\mathrm{O} 4$ antibodies were generous gifts from Dr. Anthony Campagnoni (University of California, Los Angeles). Anti-CD11b and anti-RIP antibodies were obtained from Chemicon Int. (Temecula, CA, USA). AntiED1 was from Abcam (Cambridge, MA, USA). Anti-GFAP and anti-PDGFr $\alpha$ were purchased from Neuromics (Edina, MN, USA). Anti-MMP-2 was purchased from Santa Cruz Biotechnol (Santa Cruz, CA, USA). Anti-galectin-1 antibody was prepared in G.A.R's laboratory and used as described, ${ }^{38}$ whereas anti-galectin-3 antibody was prepared in F.T.L's laboratory and used as described. ${ }^{39}$ Secondary antibodies were obtained from Jackson Immuno Research Co. Laboratories (West Grove, PA, USA).

Animals. Wistar rats were used to obtain primary cell cultures for in vitro studies. Transgenic mice that express EGFP driven by a specific oligodendroglial marker, the CNPase promoter (CNP-EGFP) were used, ${ }^{27}$ The Lgals $^{-1-}$ mice were generated and backcrossed to C57BL/6 mice for nine generations as described ${ }^{40}$ and WT C57BL/6 mice were used for in vitro and in vivo experiments. All animal protocols were approved by the Institutional Review Board of the University of Buenos Aires, and animal experimentation was in accordance with the National Institutes of Health guide for the care and use of laboratory animals.

Oligodendroglial cell cultures. Primary OLG cultures were performed as described by McCarthy and de Vellis. ${ }^{17}$ Cerebral hemispheres were dissected out from newborn rats or mice (P0-2), freed of meninges and dissociated by gentle repetitive pipetting in a mixture of DMEM and Ham's F12 $(1: 1 \mathrm{v} / \mathrm{v})$ containing $5 \mu \mathrm{g} / \mathrm{ml}$ streptomycin and $5 \mathrm{U} / \mathrm{ml}$ penicillin, supplemented with $10 \%$ fetal bovine serum (FBS). The cell suspensions were seeded in poly-L-lysine-coated $75-\mathrm{cm}^{2}$ tissue culture flasks. After 14 days in culture, microglia were separated by shaking the flasks for $30 \mathrm{~min}$ in an orbital shaker at 150 r.p.m./min, and OLGs were separated from astrocytes by continuous shaking for $24 \mathrm{~h}$ at 240 r.p.m. per minute. The cell suspension obtained was filtered through a $15 \mu \mathrm{m}$ mesh filter and then centrifuged at 1500 r.p.m. for $10 \mathrm{~min}$. OLGs were grown on poly-L-lysine-coated petri dishes $\left(2 \times 10^{6}\right.$ cells per dish) for biochemical studies or on poly-L-lysine-coated coverslips placed in multiwell plates $\left(25 \times 10^{3}\right.$ cells per well) for morphological and immunocytochemical studies. The purity of cell cultures $(>90 \%)$ was evaluated quantitatively with 04 , anti-neurofilaments and anti-GFAP antibodies. The purified oligodendroglial cells were maintained in GDM (DMEM/F12 supplemented with glucose $4 \mathrm{~g} / \mathrm{l}, \mathrm{NaHCO}_{3} 2.4 \mathrm{~g} / \mathrm{l}$, insulin $25 \mathrm{mg} / \mathrm{l}$, putrescin $8 \mathrm{mg} / \mathrm{l}$, transferrin $50 \mathrm{mg} / \mathrm{l}$, T3 $9.8 \mu \mathrm{g} /$, progesterone $20 \mathrm{nM}$, sodium selenite $8 \mu \mathrm{g} / /$ and biotin $10 \mu \mathrm{g} / \mathrm{l})$ supplemented by growth factors (PDGFAA and bFGF) for $48 \mathrm{~h}$. These cells were named OPCs. After this treatment, a cell sub-population was allowed to differentiate for $48 \mathrm{~h}$ in GDM without growth factors and named ODCs.

Primary neurosphere cultures. Lgals $3^{-1-}$ and WT newborn mice were killed by decapitation and cerebral hemispheres were dissected out. Brains were freed of meninges, dissociated and place in dishes containing DMEM F12 medium. The tissue was mechanically minced. After digestion with trypsin, the cell suspension was filtered through a $40 \mu \mathrm{m}$ Nitex (Buenos Aires, Argentina) screen and cells were collected by centrifugation at $300 \mathrm{~g}$ for $5 \mathrm{~min}$. Cells were plated in $25-\mathrm{cm}^{2}$ flasks and kept in DMEM F12 medium supplemented with B27, EGF and bFGF-2. For differentiation studies, neuroespheres were dissociated 7 days after plating, and cells were then plated in poly-ornitine-coated petri dishes in GDM. After 5 days, cells were harvested and processed for flow cytometry. The $\mathrm{O} 4$ or $\mathrm{O} / \mathrm{MBP}^{+}$cells were analyzed on a PAS III flow cytometer (Partec, Munich, Germany). Data from $2 \times 10^{4}$ cells were acquired and analyzed using FloMax software (Auckland, New Zealand).

Immunocytochemistry. Cells were fixed with 4\% PFA for 20 min, rinsed in PBS, permeabilized in $1 \%$ Triton $\mathrm{X}-100$ for 30 min (only for cytosolic antigens) and blocked with $5 \% \mathrm{FCS}$ for $2 \mathrm{~h}$. Incubation with primary antibodies was done overnight at $4{ }^{\circ} \mathrm{C}$. Sections were incubated with a fluorescent-conjugated anti-rabbit or anti-mouse secondary antibody (Cy2) for $90 \mathrm{~min}$ at $37^{\circ} \mathrm{C}$. Anti-galectin-1 (1/100), anti-galectin-3 (1/100), A2B5 (1/50) and PDGFr $\alpha(1 / 100)$ primary antibodies were used to identify immature OLGcs, whereas anti-MBP (1/25), O4 (1/50), and 01 $(1 / 100)$ were used for mature OLGs and myelin tracts, anti-GFAP $(1 / 1500)$ for astrocytes, anti-CD11b (1/100) to label macrophages/microglia, and ED1 (1/100) to stain activated microglia. Fluorescently labeled anti-rabbit, anti-mouse or anti-goat secondary antibodies (Cy2, - Сy3, 488 or 649) were used. Nuclei were labeled with the fluorescent dye Höechst $33342(5 \mu \mathrm{g} / \mathrm{ml} 1 \%$ DMSO). The preparation was mounted in Fluorsave (Merck, Darmstadt, Germany) and analyzed by UV light microscopy with an Olympus BX50 microscope (Olympus, Tokyo, Japan). Analysis was done by counting antigen-positive and Hoëchst-positive cells in 20 randomly selected fields ( $>3000$ cells for each experimental condition). Counts of antigenpositive cells were normalized to counts of total Hoechst-positive cells for each condition.

Western blot analysis. MBP isoforms were evaluated in total cell extracts of $C C$ and St from male WT and $\mathrm{Lgals}^{-1-}$ mice (4 or 8 weeks of age) and in cultured OLGs (OPCs and ODCs). Samples were lysed in TOTEX extraction buffer (Hepes pH $7.9 \mathrm{mM}, \mathrm{NaCl} 350 \mathrm{mM}$, glycerol 20\%, NP-40 1\%, MgCl $21 \mathrm{mM}$, EDTA $0.5 \mathrm{mM}$, EGTA $0.1 \mathrm{mM}$ ) with the corresponding protease inhibitors (aprotinin, leupeptin, pepstatin and PMSF). To analyze galectin-3 in OPCs and ODCs, samples were resuspended in TOTEX or RIPA ( $\mathrm{NaCl} 300 \mathrm{mM}$, TRIS $20 \mathrm{mM}$, pH 7.4, SDS $0.2 \%$ ) with protease inhibitors. Protein concentration was determined using a BioRad kit (Bio Rad, Hercules, CA, USA). Equal amounts of the proteins were separated on SDS-PAGE gels and transferred onto PVDF membranes for western blot analysis. Membranes were incubated with anti-MBP $(1: 2000)$ or anti-galectin-3 $(1: 1000)$ antibodies, followed by incubation with peroxidase-conjugated secondary antibodies. Quantification was conducted using a Gel Pro Analyzer 4.0 system (Gel Pro Analizer Media Cybernetics Gel Pro Analyzer, Bethesda, MD, USA).

N20.1 cell line cultures. The immortalized OLG cell line N20.1 (kindly supplied by A.T. Campagnoni, UCLA) was grown in DMEM/F12, 10\% FBS, $0.01 \%$ G418 at $34^{\circ} \mathrm{C}$ until $100 \%$ confluence. To allow their differentiation, cells were placed at $39^{\circ} \mathrm{C}$ in GDM $1 \%$ FBS.

Luciferase assay of MBP promoter constructs. N20.1 cell line was grown in 48-well plates ( 10000 cells per well) containing DMEM/F12 10\% FBS and G418 at $34^{\circ} \mathrm{C}$ and transfected using $25 \mu \mathrm{l}$ of a transfection mixture $(100 \mu \mathrm{l}$ OptiMEM, $5 \mu$ l Lipofectamine $2000,400 \mathrm{ng}$ firefly Luciferase reporter DNA, -52 , -105, -mut105, -333, -513, -717, -835, -1176, -1323 MBP-promoter-Luc-constructs and $100 \mathrm{ng}$ pRL-SV40-Rluc) (Promega, Madison, WI, USA). Renilla luciferase (Rluc) was used as an internal control for normalizing transfection efficiency. The MBP-luciferase constructs were prepared as described. ${ }^{18}$ The Firefly and Renilla Luciferase activities were sequentially measured using the Dual-Luciferase kit (Promega) in a Junior LB 9509 luminometer (Berthold Technologies, Dak Ridge, TN, USA) according to the manufacturer's instructions. Each set of two transfections was repeated three times.

Gelatin zymography. OLGs $\left(2 \times 10^{6}\right.$ cells per dish) grown in GDM were harvested for gelatin zymography. Gelatinolytic regions were observed as white bands against a blue background. Gels were scanned for semiquantitative evaluation of band intensities. All experiments were performed at least in triplicate and representative experiments are shown. To identify the specific metalloprotease involved in the observed effects, sister blots were done using an anti-MMP-2 antibody $(1: 200)$ (Santa Cruz).

Glycophenotypic analysis. Cells were incubated as described ${ }^{9}$ with biotinylated SNA $(20 \mathrm{mg} / \mathrm{ml}$; E-Y Labs, San Mateo, CA, USA), PNA $(20 \mathrm{mg} / \mathrm{ml}$; Sigma, St. Louis, MO, USA) or MAL II (20 mg/ml; Vector, Burlingame, CA, USA) followed by fluorescein isothiocyanate-conjugated streptavidin. Nonspecific binding was determined for fluorescein isothiocyanate-conjugated streptavidin alone. Cells were processed in a FACSAria flow cytometer (BD Bioscience, San Diego, CA, USA).

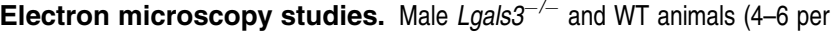
group) were decapitated at 4 and 8 weeks of age. CC and St were dissected out, fixed and immediately prepared for electron microscopy. Ultrathin cuts were examined using a Zeiss Leo 906E electron microscope equipped with the digital camera Megaview III (Zeiss, Oberkochen, Germany). Different myelin parameters of the CC and St of $\mathrm{Lgals}^{-1-}$ and WT mice were submitted to quantitative evaluation: (a) percentage of correctly myelinated axons per field; (b) ratio between the axon's 
diameter wrapped with myelin and axon's diameter, defined as g-ratio; (c) number of myelin turns around an axon; and (d) the width of the compact myelin in different axons. An average of eight electron micrographs for each experimental condition was considered. Image $\mathrm{J}$ software was used for image analysis.

Behavior tests. Male $\mathrm{Lgals}^{-/-}$and WT mice (9-13-weeks old) were housed in groups of four animals in a controlled environment $\left(20-23^{\circ} \mathrm{C}\right)$ with free access to food and water and maintained on a $12 \mathrm{~h} / 12 \mathrm{~h}$ day/night cycle, with light on at 0600 hours. The behavioral experiments were performed between 1000 and 1400 hours with intervals of $24 \mathrm{~h}$ between different behavioral tests. The following assays were performed: plus-maze, hole-board, locomotor activity and inverted screen tests to measure anxiety, exploration, locomotor activity and motor coordination, respectively, as described in Supplementary Methods online.

Statistical analysis. Graph-Pad Prism Software was used for data analysis. Results are presented as mean \pm standard error of the mean (S.E.M.). Comparisons were performed using unpaired one-tailed Student's $t$-test or oneway analysis of variance (ANOVA) followed by Bonferroni post-hoc tests, where appropriate. Data from the plus maze, hole-board and locomotor activity tests were analyzed with unpaired $t$-tests. Data from the inverted screen test were analyzed with chi-square test. A $P$-value less than 0.05 was considered statistically significant.

\section{Conflict of Interest}

The authors declare no conflict of interest.

Acknowledgements. We wish to thank Vittorio Gallo for kindly providing CNP-EGFP mice. This work was supported by grants from the National Agency for Promotion of Science and Technology (Argentina) to JMP, LAP and GAR, and from the National Council of Scientific and Technical Investigation (Argentina), University of Buenos Aires, and Fundación Sales (Argentina) to GAR.

1. Bhat R, Steinman L. Innate and adaptive autoimmunity directed to the central nervous system. Neuron 2009; 64: 123-132.

2. Bansal R, Stefansson K, Pfeiffer SE. Proligodendroblast antigen (POA), a developmental antigen expressed by A007/04-positive oligodendrocyte progenitors prior to the appearance of sulfatide and galactocerebroside. J Neurochem 1992; 58: 2221-2229.

3. Rabinovich GA, Toscano MA, Jackson SS, Vasta GR. Functions of cell surface galectinglycoprotein lattices. Curr Opin Struct Biol 2007; 17: 513-520.

4. Yang RY, Rabinovich GA, Liu FT. Galectins: structure, function and therapeutic potential. Expert Rev Mol Med 2008; 10: e17.

5. Rabinovich GA, Toscano MA. Turning 'sweet' on immunity: galectin-glycan interactions in immune tolerance and inflammation. Nat Rev Immunol 2009; 9: 338-352.

6. Toscano MA, Bianco GA, llarregui JM, Croci DO, Correale J, Hernandez JD et al. Differential glycosylation of $\mathrm{TH} 1, \mathrm{TH} 2$ and $\mathrm{TH}-17$ effector cells selectively regulates susceptibility to cell death. Nat Immunol 2007; 8: 825-834.

7. Ilarregui JM, Croci DO, Bianco GA, Toscano MA, Salatino M, Vermeulen ME et al. Tolerogenic signals delivered by dendritic cells to $T$ cells through a galectin-1-driven immunoregulatory circuit involving interleukin 27 and interleukin 10. Nat Immunol 2009; 10: 981-991.

8. Jiang HR, Al Rasebi Z, Mensah-Brown E, Shahin A, Xu D, Goodyear CS et al. Galectin-3 deficiency reduces the severity of experimental autoimmune encephalomyelitis. J Immunol 2009; 182: 1167-1173.

9. Reichert F, Rotshenker S. Galectin-3/MAC-2 in experimental allergic encephalomyelitis. Exp Neurol 1999; 160: 508-514.

10. Horie H, Inagaki $Y$, Sohma $Y$, Nozawa R, Okawa K, Hasegawa M et al. Galectin-1 regulates initial axonal growth in peripheral nerves after axotomy. J Neurosci 1999; 19: 9964-9974.

11. Sakaguchi $M$, Shingo $T$, Shimazaki $T$, Okano HJ, Shiwa M, Ishibashi $S$ et al. A carbohydrate-binding protein, Galectin-1, promotes proliferation of adult neural stem cells. Proc Natl Acad Sci USA 2006; 103: 7112-7117.

12. Plachta N, Annaheim C, Bissière S, Lin S, Rüegg M, Hoving S et al. Identification of a lectin causing the degeneration of neuronal processes using engineered embryonic stem cells. Nat Neurosci 2007; 10: 712-719.
13. Pesheva P, Kuklinski S, Schmitz B, Probstmeier R. Galectin-3 promotes neural cell adhesion and neurite growth. J Neurosci Res 1998; 54: 639-654.

14. Gustavsson P, Linsmeier CE, Leffler H, Kanje M. Galectin-3 inhibits Schwann cell proliferation in cultured sciatic nerve. Neuroreport 2007; 18: 669-673.

15. Sasaki T, Hirabayashi J, Manya H, Kasai K, Endo T. Galectin-1 induces astrocyte differentiation, which leads to production of brain derived neurotrophic factor. Glycobiology 2004; 14: 357-363.

16. Rotshenker S, Reichert F, Gitik M, Haklai R, Elad-Sfadia G, Kloog Y. Galectin-3/MAC-2, Ras and PI3K activate complement receptor-3 and scavenger receptor-AI/II mediated myelin phagocytosis in microglia. Glia 2008; 56: 1607-1613.

17. McCarthy KD, de Vellis J. Preparation of separate astroglial and oligodendroglial cell cultures from rat cerebral tissue. J Cell Biol 1980; 85: 890-902.

18. Calatayud CA, García CI, Paez PM, Pasquini JM, Soto EF, Pasquini LA. Partial inhibition of the proteasome enhances the activity of the myelin basic protein promoter. Dev Neurosci 2009; 31: 169-180.

19. Casaccia-Bonnefil P, Tikoo R, Kiyokawa H, Friedrich Jr V, Chao MV, Koff A. Oligodendrocyte precursor differentiation is perturbed in the absence of the cyclindependent kinase inhibitor p27 kip1. Genes Dev 1997; 11: 2335-2346.

20. Le Mercier M, Fortin S, Mathieu V, Kiss R, Lefranc F. Galectins and gliomas. Brain Pathol 2010; 20: 17-27.

21. Ochieng J, Fridman R, Nangia-Makker P, Kleiner DE, Liotta LA, Stetler-Stevenson WG et al. Galectin-3 is a novel substrate for human matrix metalloproteinases-2 and -9 . Biochemistry 1994; 33: 14109-14114.

22. Wu MH, Hong TM, Cheng HW, Pan SH, Liang YR, Hong HC et al. Galectin-1-mediated tumor invasion and metastasis, up-regulated matrix metalloproteinase expression, and reorganized actin cytoskeletons. Mol Cancer Res 2009; 7: 311-318.

23. Yuan X, Chittajallu R, Belachew S, Anderson S, McBain CJ, Gallo V. Expression of the green fluorescent protein in the oligodendrocyte lineage: a transgenic mouse for developmental and physiological studies. J Neurosci Res 2002; 70: 529-545.

24. Yang Z, Levison SW. Hypoxia/ischemia expands the regenerative capacity of progenitors in the perinatal subventricular zone. Neuroscience 2006; 139: 555-564.

25. Orentas DM, Miller RH. Regulation of oligodendrocyte development. Mol Neurobiol 1998; 18: 247-259.

26. Li H, He Y, Richardson WD, Casaccia P. Two-tier transcriptional control of oligodendrocyte differentiation. Curr Opin Neurobiol 2009; 19: 479-485.

27. Hamilton SP, Rome LH. Stimulation of in vitro myelin synthesis by microglia. Glia 1994; 11: 326-335.

28. Ellison JA, de Vellis J. Amoeboid microglia expressing Gd3 ganglioside are concentrated in regions of oligodendrogenesis during development of the rat corpus callosum. Glia 1995; 14: 123-132.

29. Svedin P, Hagberg H, Mallard C. Expression of MMP-12 after neonatal hypoxic-ischemic brain injury in mice. Dev Neurosci 2009; 31: 427-436.

30. Puche AC, Poirier F, Hair M, Bartlett PF, Key B. Role of galectin-1 in the developing mouse olfactory system. Dev Biol 1996; 179: 274-287.

31. Ishibashi S, Kuroiwa T, Sakaguchi M, Sun L, Kadoya T, Okano H et al. Galectin-1 regulates neurogenesis in the subventricular zone and promotes functional recovery after stroke. Exp Neurol 2007; 207: 302-313.

32. Kajitani K, Nomaru H, Ifuku M, Yutsudo N, Dan Y, Miura T et al. Galectin-1 promotes basal and kainate-induced proliferation of neural progenitors in the dentate gyrus of adult mouse hippocampus. Cell Death Differ 2009; 16: 417-427.

33. Sakaguchi M, Imaizumi Y, Okano $\mathrm{H}$. Expression and function of galectin-1 in adult neural stem cells. Cell Mol Life Sci 2007; 64: 1254-1258.

34. Hirabayashi J, Hashidate T, Arata $Y$, Nishi N, Nakamura T, Hirashima M et al. Oligosaccharide specificity of galectins: a search by frontal affinity chromatography. Biochim Biophys Acta 2002; 1572: 232-254.

35. Li C, Tropak MB, Gerlai R, Clapoff S, Abramow-Newerly W, Trapp B et al. Myelination in the absence of myelin-associated glycoprotein. Nature 1994; 369: 747-750.

36. Levine JM, Nishiyama A. The NG2 chondroitin sulfate proteoglycan: a multifunctional proteoglycan associated with immature cells. Perspect Dev Neurobiol 1996; 3: 245-259.

37. Torkildsen O, Brunborg LA, Myhr KM, Bø L. The cuprizone model for demyelination. Acta Neurol Scand Suppl 2008; 188: 72-76.

38. Dettin L, Rubinstein N, Aoki A, Rabinovich GA, Maldonado CA. Regulated expression and ultrastructural localization of galectin-1, a proapoptotic beta-galactoside-binding lectin, during spermatogenesis in rat testis. Biol Reprod 2003; 68: 51-59.

39. Acosta-Rodriguez EV, Montes CL, Motrán CC, Zuniga El, Liu FT, Rabinovich GA et al. Galectin-3 mediates IL-4-induced survival and differentiation of B cells: functional cross-talk and implications during Trypanosoma cruzi infection. J Immunol 2004; 172: 493-502.

40. Sano H, Hsu DK, Apgar JR, Yu L, Sharma BB, Kuwabara I et al. Critical role of galectin-3 in phagocytosis by macrophages. J Clin Invest 2003; 112: 389-397. 